\title{
Domestic Violence or Elder Abuse? Why It Matters for Older Women
}

Teresa Kilbane

Loyola University Chicago, tkilban@luc.edu

Marcia K. Spira

Loyola University Chicago

Follow this and additional works at: https://ecommons.luc.edu/socialwork_facpubs

Part of the Social Work Commons

\section{Recommended Citation}

Teresa Kilbane and Marcia Spira (2010) Domestic Violence or Elder Abuse? Why It Matters for Older Women. Families in Society: The Journal of Contemporary Social Services: 2010, Vol. 91, No. 2, pp. 165-170.

This Article is brought to you for free and open access by the Faculty Publications and Other Works by Department at Loyola eCommons. It has been accepted for inclusion in Social Work: School of Social Work Faculty Publications and Other Works by an authorized administrator of Loyola eCommons. For more information, please contact ecommons@luc.edu. c) $($ ) $\Theta$

This work is licensed under a Creative Commons Attribution-Noncommercial-No Derivative Works 3.0 License. (c) Alliance for Children and Families, 2010. 


\title{
Domestic Violence or Elder Abuse? Why It Matters for Older Women
}

\author{
Teresa Kilbane \& Marcia Spira
}

\begin{abstract}
Law enforcement and legal services are 2 systems that respond to reports of abuse against women through programs such as adult protective services (APS) and domestic violence (DV). APS and DV systems operate independently and define the cause of the abuse differently. The designation of a woman as having suffered domestic violence or having been abused often depends on which system she enters. This designation can lead to different options for women to obtain services. Aging may further complicate access and usability of these systems to respond to the needs of abused elderly. Using vignettes, this article explores the definitions of abuse and highlights specific concerns of aging that impact usefulness of services.
\end{abstract}

\section{Implications for Practice}

- Women must be able to identify abuse in their own lives and have access to help from multiple systems in order to receive options of a full range of services.

- DV and APS programs must eliminate the barriers that older women face in trying to access services.

- Workers in different systems must be sensitized to work with issues of domestic violence as well as the specific concerns of older victims.

T he distinctions between domestic violence and elder abuse are ambiguous and blurred. The two main systems that respond to the problem of abuse against older women are adult protective services (APS) and domestic violence (DV) programs. Each system operates independently and differs in (a) the definitions and model upon which services are based, (b) the type of services offered to the victim and how safety and protection are determined, (c) the specific training of workers, and (d) how incidents of abuse are reported. APS, often compared to the model of child protective services, develops out of the belief that older adults require specific protections due to their vulnerability and disability. Elder abuse investigations supported by the APS system define multiple types of abuse and abusers, some of whom are domestic partners. Domestic violence services evolve from feminist theory, emphasizing an empowerment model. DV can be narrowly defined as intimate partner violence with the focus primarily on younger women and their children (Otto \& Quinn, 2007, p. 1).

However, in some states "domestic" abusers include adult children, other family members, and some caregivers. There is a lack of standards in definitions provided by these two systems, creating shortcomings in both systems (Hightower, 2002). There is a lack of centralized reporting of cases, hindering accurate accounts of its prevalence. Additional limitations in the training of workers in each system narrow the knowledge of the resources, services, and skills each group conveys to clients. Therefore, although older abused women should be able to access and use both domestic violence programs and adult protective services, they generally do not. There is agreement among professionals that neither system "has been particularly successful at understanding and meeting the needs of older women who are abused by intimate partners and family members" (Brandl \& Cook-Daniels, 2002, p. 1).

\section{Definitions of Abuse in Later Life}

In the earliest days of elder abuse research, abuse of older women was described as the result of cumulative "caregiver stress," created by the unrelenting needs of a dependent older person (Nerenberg, 2002). Caregiver stress was explained as the result of the burdens of care (Zarit \& Toseland, 1989). Often, caregiver stress has been related to the presence of dementia and a decline in the ability of the victim to perform the activities of daily living or more complex activities like meal planning, grocery shopping, and check reconciliation. However, research has demonstrated that many caregivers who provide a great deal of care to impaired older adults are not highly stressed, while many who provide a lesser degree of care to older adults are extremely stressed (Nerenberg, 2002). Some researchers believe that elder abuse has more to do with the characteristics of the abuser, rather than the dependence of the victim (Paveza, Cohen, \& Eisdorfer, 1992). This notion is supported by research that associates mood disturbances in the caregiver, not the burden of care, as a cause of elder abuse (Coyne, Reichman, \& Berbig, 1993).

As elder abuse literature evolves, it becomes clear that multiple causes of elder abuse exist. In particular, the dynamic of power and control, so 
prevalent in domestic violence theory, is now commonly identified in the elder abuse literature (Pillemer \& Finklehor, 1989; Wolf, 1998). Lundy and Grossman (2004) report that trends in research demonstrate this redirection from caregiver stress to the issue of ongoing domestic violence in the context of power and control dynamics. In many cases, the power and control relationship between the victim and the abuser are more predictive of abuse than the age or capacity of the woman. Brandl and Raymond describe such a pattern of coercive control and a sense of entitlement on the part of the perpetrator, in the presence of an ongoing and trusting relationship (as cited in Otto \& Quinn, 2007, p. 61).

However, the designation of a woman as having suffered domestic violence or elder abuse is still often dependent on which system she enters. The admission to one system or the other is often determined by age. The definition of the victim in elder abuse generally includes anyone over age 60 , resides in a domestic situation, and is abused by another individual. The perpetrator has to be known to the older victim. Often the abuser is a family member or caregiver. Researchers report that the older victim in domestic violence situations is generally over age 50, though this finding has varied widely (Klein, Tobin, Salomon, \& DuBois, 2007). Another variation in admission to either system is the degree to which the women can speak for themselves. In elder abuse there is an assumption that older women are frail, impaired, and unable to advocate for themselves; the domestic violence programs assume that women are disempowered in the coercive relationship, but capable of providing for their own needs. Despite the variance in age and capacity for self-advocacy, the distinctions between elder abuse and domestic violence remain vague and blurred.

There are significant differences in the language used by each system to identify the women (Otto \& Quinn, 2007). For instance, in elder abuse the clients are referred to as "victims;" in domestic violence the clients are referred to as "survivors." These different perceptions of women may contribute to distinctly different views of the women and their needs for particular services. A victim may be viewed through a more paternalistic lens and regarded as needing others to make decisions about care. Use of services such as reducing stress in the home through respite services or home health services or movement to assisted living facilities may be recommended. A survivor may be regarded as someone possessing a resilience to move toward a state of independence and freedom from the abuse. Services in the form of crisis intervention, safety planning, or temporary stays in shelters may be indicated.

The same discrepancies in perceptions of the women's needs for services may be further perpetuated by the initiation of reports. Older abused women are often afraid or unable to report to elder abuse agencies on their own. Often, the reporters of elder abuse are mandated by the state to inform adult protective agencies of suspected abuse. Reports may also be voluntary from nonmandated reporters. National Center on Elder Abuse (NCEA) regulations state that reports are to be made on behalf of individuals who are vulnerable due to age (or disability) and are unable to report on their own (NCEA, 2006). It is up to the reporters to determine whether the women are able to report on their own. It is possible that errors in judgment are made, but most states encourage reports that err on the side of the women's lack of capacity than on the assumption the women will report if they wish to obtain help. These reporters are generally health care providers, social service workers, or law enforcement staff. Reporters of domestic violence are often the victims themselves. The problem is that the source of the report and the agency to which the situ- ation is reported may strongly influence the system to which the women are directed. There is little information on the criteria that well-meaning reporters use in choosing which system to issue reports.

The fact that the mistreatment as defined by each system does not clearly distinguish elder abuse from domestic violence leads to the possibility of more ambiguity between the systems. NCEA (2006) defines the types of elder abuse as physical, psychological, sexual, abandonment, neglect, self-neglect, and financial exploitations. According to an Illinois statute, domestic violence includes physical abuse, threats that put the person in fear of physical harm, unlawful imprisonment, harassment, stalking, intimidation of a dependent, or interference with personal liberty. The prevalence of financial abuse is present in both systems.

Couples who experience violent interactions for decades often continue the same pattern after the age of 60 . However, there seems to be a misperception that domestic violence is a problem for younger women, limiting attention to the unique needs of older women (Hightower, 2002). In fact, research has begun to recognize that many older women are victims of domestic violence throughout the course of long-term relationships (Lundy \& Grossman, 2004). Abuse in later life is viewed as the intersection between elder abuse and domestic violence (Brandl, 2005). Abuse that begins as domestic violence crosses into the realm of elder abuse once the women reach 60 years of age. Brandl and CookDaniels (2002) suggest use of the term "abuse in later life" to cover both elder abuse and domestic violence. They view domestic violence in later life as a distinct subset of elder abuse. The Illinois Department on Aging (2009) uses the term "domestic violence grown old" to describe domestic abuse of older women and "abuse in later life as domestic violence and a distinct subset of elder abuse" (p. 9).

\section{Who Are the Abusers?}

Definitions of abusers are also blurred by a lack of standards between the two systems. The laws regarding elder abuse and domestic violence in each state designate the types of relationships included in the respective definitions. There is agreement that both elder abuse and domestic violence identify the spouse or domestic partner as perpetrators in their definitions. According to an early survey of elder abuse, Pillemer and Finkelhor (1989) "suggest[ed] that the majority of the projected 701,000 to $1,093,560$ abused elders in the U.S. [are] victims of spouse abuse" (p. 6). Lundy and Grossman (2004) reported that approximately $51.3 \%$ of the perpetrators of domestic violence in Illinois from 1990 to 1995 could be classified as intimate partners. According to the NCEA (2006), data from 11 responding states indicate that most alleged perpetrators are adult children $(32.6 \%)$, a spouse or intimate partner (11.3\%), and other family members (21.5\%).

However, there is inconsistency between the states in their statutory definitions of perpetrators of domestic violence. In some states adult children and caregivers are included in the definition while in others they are not (Brandl \& Cook-Daniels, 2002). The result is that the identification of the abusers and the abusers' relationship to the victims leads to continued confusion about selecting the right system to which to report the incidents of abuse.

\section{Prevalence of Domestic Violence Against Older Women}

It is estimated that more than 13,000 women in the United States over the age of 55 report incidents of intimate partner abuse (Rennison \& Rand, 2003). Only about 1 in 13 cases of elder abuse are reported to 
the Elder Abuse and Neglect Program. It is estimated that $50 \%$ of elder abuse reports allege financial exploitation, approximately $25 \%$ allege physical abuse, $45 \%$ allege active or passive neglect, and $45 \%$ allege emotional abuse. According to the 2004 survey of state adult protective services (APS), there was a $19.7 \%$ increase in combined total of reports of elder and vulnerable adult abuse and neglect-a 15.6\% increase in substantiated cases in the 4 years since the last survey in 2000 .

In a white paper on elder abuse, Wood (2006) reported that in 2005 the National Domestic Violence Hotline, out of a total of 201,064 calls, received some 7,172 calls - $3.5 \%$ of callers - from people who were older than age 55. The number of older women being reported as victims of abuse is on the rise. However, researchers and statisticians have not been consistent about keeping records in the breakdown of ages from 50 to 65 and up. There is a lack of centralized reporting mechanisms, resulting in age more than the type of abuse being the determining factor in referral.

One important aspect to consider is the referral and use of services by women from ethnic minorities. Although women of color may be underrepresented in studies of assessment, there are significant differences that can be found between referrals to domestic violence programs and adult protective services. Grossman and Lundy (2003) detailed some of these differences:

1. Hispanic clients are less likely to be referred by social agencies or friends and more likely to be referred by legal sources.

2. The largest proportion of White and African American women are likely referred to domestic violence programs by police, followed by social service agencies.

3. Older White female victims of abuse are more likely to enter the system on their own.

4. All ethnic groups have similar needs for shelter or housing assistance.

5. African American clients are less likely to report personal emotional support needs.

6. White clients reported less need for legal assistance.

These differences may indicate differential access to systems, but also suggest that the source of the referral may have greater knowledge of one system over the other; be uninformed about the range of options; or may have personal biases derived from a variety of other sources, including training or personal experience. For instance, medical personnel are more likely to refer older women to APS rather than DV programs, possibly due to more familiarity with APS programs.

Grossman and Lundy (2003) also find that the depiction of abuse among older women derived from DV program data is different from that which comes from the APS data, which has serious implications for intervention:

1. Intimate violence reports comprise more than $50 \%$ of cases among White and Hispanic women and more than $40 \%$ among reports for African American women.

2. Data from DV programs report more physical, emotional, and sexual abuse than data from APS studies, in particular, and more sexual abuse among Hispanic clients.

Another important consideration is that one's culture and background impact how the older person defines abuse, and thus has implications on public awareness efforts to recognize these differences. Brandl and Cook-Daniels (2002) reviewed 12 articles published in this area. One review is a study of African American, Korean American, and White elders, age 60 and older, living in Los Angeles (Moon \& Benton, 2000). Their study suggests that ethnic differences require ethnicspecific approaches to be more effective in outreach efforts to elders.

\section{Differences in Services: Why It Matters}

The main reason why understanding the distinctions of each system matters is that the services available to women are linked to the designated system. Vinton (1991) first described the complications for women seeking help. In order for older women who have allegedly been abused by a spouse to receive services from APS, mandated reporters must believe the women cannot report on their own. If the abuse is substantiated by elder abuse investigators, discussions of safety plans may even be included in the treatment planning. However, if the women have capacity to report on their own, some states preclude them from receiving services from state APS agencies. These women may be reluctant to engage help from DV programs (Beaulaurier, Seff, Newman, \& Dunlop, 2007).

In any case, reports of suspected elder abuse will propel an evaluation by APS despite the woman's degree of frailty. However, once in the domain of APS, it is highly unlikely that the woman will receive services of the DV programs and interventions often minimize the abuse as a violation of the law (Otto \& Quinn, 2007). Anecdotal evidence suggests that many elder abuse investigators accept clients who are over the age of 60 based on age criterion alone and do not refer to domestic violence programs (Kilbane, 2007). Elder abuse investigators, schooled in the theory of caregiver stress, may work to alleviate the "burden" on the caregiver through home health services, caregiver support groups, or respite care. In this case, the victim is unlikely to receive services afforded to women who are victims of domestic abuse, such as shelter, crisis intervention, and peer support groups. Even when services are available, experts are realizing that older victims simply do not show up at shelters or call police but suffer in silence (Hightower, 2002). If reports to APS are initiated, the worker will make an unannounced home visit. Elder abuse investigators are rarely trained in the dynamics of family violence and the home visit may trigger more acts of violence. In these cases the victim may be in even more danger if she remains in the home.

The problems are created by the lack of collaboration between the systems (Hightower, 2002). This lack of collaboration creates barriers in sharing resources and limits the options for continuity of care. Vinton (1991) reports that DV programs "have virtually ignored older women" (p. 6). Unfortunately, this trend, while slowly changing in response to an increased number of older women seeking help from DV programs, still seems prevalent. Paranjape, Tucker, McKenzie-Mach, Thompson, and Kaslow (2007) state that domestic violence programs are fairly inaccessible to older women. Access to domestic violence programs for older women is very difficult. Hightower (2002) feels that these women become part of the elder abuse system rather than the domestic violence system simply on the basis of age. This assumption results in sustaining a distorted view of older women. They are understood most frequently through a medical model, which focuses on frailty and lack of the capacity to perform activities of daily living. The consequence of this perspective is a failure of advocates and service providers in the area of violence against women to view the abuse of older women through the lenses of gender and power. Attempts to empower older women who retain capacity may be overlooked.

Another aspect of this limitation is that a woman's perception of herself is influenced by the system to which she is referred. Vinton (1991) 
recognized that older women might not seek available services because their own perception of their situation is limited to one-system definitions. Recommendations for educating women about abuse through pubic health programs and social services are encouraged (Wisconsin Coalition Against Domestic Violence, 2006).

\section{Vignettes to Depict the Problem}

Marge is a 67-year-old woman who often walked past a shelter for abused women in her neighborhood. On a regular basis she imagined how her life would be inside. She was by all accounts a battered woman. For the last 5 years of her 43-year marriage, her husband's alcohol use had increased as did his erratic and violent behavior toward her. He had always "been in charge" of their life, keeping track of Marge's management of the house. He even told her what to cook, how to dress, and whom to be friends with in the neighborhood. When Marge had attempted to develop her own interests and expressed a desire to work outside of the home, her husband "convinced" her to keep things as they were. She knew he was really dependent on her to take care of his needs and she quickly gave up her own aspirations.

Marge was always too embarrassed to talk to anyone about her husband's behavior. She believed his behavior was a reflection on her, so she kept his actions a secret. For many years she believed that if she just did things the way her husband wanted them done, everything would be all right. However, as her arthritis crippled her, she was fearful of needing more help. She believed her condition worsened from all of the stress she endured in her marriage. She used a walker to help her maintain balance and negotiate sidewalks and street crossings. She also had diabetes and required insulin injections twice daily. She was able to give herself injections, but sometimes needed help filling the syringes. Marge's husband threatened her and sometimes refused to fill her syringes when asked. Marge wanted help, but did not want to get her husband in trouble. She was unwilling to call the police or force her husband from her home. She feared the police would not believe her and then her husband would get "really mad."

Marge knocked on the door of the shelter and asked to speak to one of the women who worked there whom she had met in the grocery store. She told the woman that her husband didn't mean any harm; he just had a bad temper and was sometimes mean. The worker invited her inside and told her she could stay for the evening, though no one was available to help her with her medical needs. Marge did not feel she "fit" with the women who were 30-40 years younger than her. She was frightened that the small children might knock her off-balance and cause her to fall. Marge did not stay at the shelter.

Typical of older women who need help from shelters, Marge had medical conditions that could not be managed by the shelter. She was also uncomfortable with the lack of people her age, and some parts of the facility were physically inaccessible to her. Frightened that her husband would be angry if she stayed away, concerned about getting her insulin, and feeling like she did not fit in the shelter, Marge went back home without follow-up or referral.

Paula is 79 years old, and she lives with her 60-year-old husband. In recent months he seems to be exasperated by her declining abilities to provide self-care. She is afflicted with Parkinson's disease and was diagnosed with mild cognitive impairment. They had separate rooms in their three-bedroom home. She acknowledged that she was dependent upon him. She also was prone to depression. Her husband provided all of her care, helping her to bathe, dress, and navigate the several stairs in their split-level home. However, he often handled his wife roughly, and when she would cry out in pain, he would yell at her and call her names. He had started to drink more heavily, reverting to old patterns of behavior. When Paula fell down two stairs in their home she was taken to the hospital. She was very thin and had multiple bruises over her body. She told the nurse that her husband had "accidentally" pushed her and she "lost her balance." She insisted that she wanted to go home. The couple was discharged home after being referred to a social worker, who called in APS.

A social worker came to Paula's home to do an assessment. Paula felt like she had overburdened her husband and was entirely to blame for the mistreatment she received. Though the social worker believed that the behavior of Paula's husband was abusive, she felt that he was overstressed from providing all of Paula's care. The social worker offered Paula's husband some time off so that he could reduce his stress levels. She recommended a home health agency from which someone would come to look after Paula, but Paula was afraid of strangers. She did not want an unfamiliar woman coming to help her bathe, assist her in dressing, or get her meals. She refused help, deteriorated over the course of several months, and appeared to be more confused and cognitively impaired. Her husband was advised to petition for guardianship, hoping to move his wife to a long-term care facility.

Paula, unlike Marge, did not choose to seek services. Concerns about her welfare were raised when she presented at the hospital with a potential injury. While she refused service, her husband was offered help in the form of time off and he proceeded to consider petitioning for guardianship that would adjudicate Paula as incompetent to care for herself. This action, if granted, would remove all of Paula's rights to make decisions on her own.

These vignettes depict two women who share much in common. Though both Paula and Marge suffered mistreatment from their respective husbands, each woman's entry into a different system may alter the perception of the abuse, the abuser, and available services.

\section{Discussion}

Problems that evolve from dichotomous views of abuse are illustrated in the previous vignettes. Marge and Paula are older women who are both abused. However, each of them has limited options available due to the designation of their plight by two different systems. Each one is frustrated by the limits of service available to them. First, it is common to internalize messages of blame for the abuse. Both Marge and Paula feel they are to blame for their husbands' behavior. They both assume the condition of their health explains the erratic and aggressive behaviors of their spouse.

Marge's husband seems to fit the profile of a controlling husband who felt he could exert power over his subservient wife. Clearly alcohol and substance abuse exacerbate the problem-and Marge's husband increased his use of alcohol (perhaps) as stress increased. They are a couple that exemplifies domestic abuse grown old. Marge has been physically and emotionally mistreated by her husband for much of her married life. As her physical impairments necessitated great dependency and needs for help, her options became more limited. She was reluctant to call legal authorities due to her own sense of dignity and also for fear of retaliation from her husband. When she finally feels enough courage to go to the shelter, she realizes that it offers her no more assistance than her husband. She feels self-conscious and out of place with the other residents. In the end she returns home with little expectation for change in her life.

Paula's husband's behaviors were viewed as the result of the strain of providing care for his wife. His intentions were never viewed as 
anything less than cumulative caregiver stress. Paula also was concerned about retaliation. She was fearful of being institutionalized or losing her independence through guardianship procedures. Her entry into the elder abuse system was through a referral from the hospital. This is not an uncommon route. However, since she did not make the decision herself, she felt powerless. Her insistence to return home was met with an evaluation of her judgment and capacity to make sound decisions for her care. Rather than receiving support and understanding of her needs, the focus shifts to the alleviation of stress within the house.

Marge and Paula are limited by their medical needs, and this contributes to the maintenance of the status quo. They are both at an age when their social circles may be shrinking and they feel more dependent on the abuser for social contact as well as having fewer options to call on friends for help.

Both vignettes also illustrate the ambiguity of which system could be more helpful. It is clear that the services that were created to offer these women support inadequately met their needs and failed to help establish a sense of safety. Integrating aspects of both systems could have served as the support these women needed by creating greater possibilities for each of them to find peace in their own homes. Otto and Quinn (2007) report on several efforts taking place in the United States to assist in their collaboration. These efforts usually involve APS and DV workers responding in teams, being part of an interdisciplinary review team or interagency workgroup, and surveys to assess program awareness of each discipline by the other party. An example of such integration follows.

\section{Example of a Collaboration}

Ms. D, a 66-year-old African American woman, came to DV court ostensibly to get an order of protection. Her ex-husband (she was married to him for 40 years prior to leaving him) was "rough" with her and her face was swollen from his alleged abuse. She came to court very reluctantly with her daughter, who demanded that her mother get an order to keep "that monster" away from her. The judge asked Ms. D about her reluctance and Ms. D began to cry, stating that she couldn't manage the house and the entire repair it required on her own. She also had physical problems that made her negotiation of parts of the house difficult. She said that her former husband said that he still loved her and that he would come by and "fix things up" for her. That is when she was allegedly abused. The judge happened to ask the woman how old she was, and upon learning that she was 66 , the judge asked that a referral to APS be made in addition to granting an order of protection. In this particular court a pilot program had been instituted in which an interdisciplinary team comprised of a social worker from APS, a worker from DV, and a law student worked together on assessments and recommendations. The judge referred the case to the team. The APS workers came to the house and did a comprehensive assessment, learning that Ms. D could make use of some social services that would help her to live independently in her home. The DV worker suggested that Ms. D go to a shelter, but the shelter had no facilities to take care of her needs (she was arthritic and used a walker). The team found a temporary group home in which Ms. D could stay while legal options were explored. The team was able to offer her legal assistance to get an order of protection. Ultimately, Ms. D's husband agreed to stay away from her (in accordance with the order from the court), Ms. D returned to her home with a volunteer program to check on her regularly, and services were secured to repair her home and make it handicapped accessible.

\section{Conclusion}

It is critical that women are able to identify the problem of abuse in their own lives and have access to a range of services to get help. They should not be hindered by barriers created between programs. Obstacles created by bureaucratic idiosyncrasies like absence of age data, lack of resources for older women, or limitations in training of workers must be overcome in order to ensure that women who are the victims of partner abuse have options for their care. Recommendations to address these barriers should include access to the age of women when they request services. Older women could be routinely referred for services to adult protective services and to workers who have been trained in issues of domestic violence. Respite care and shelters designed for the needs of older women should be developed and funded. Workers from both settings should receive updated training and develop skills in collaboration.

Current theories of abuse tend to be too one dimensional. In both the APS and DV systems, most cases go unreported, a situation which may reflect the need for reform. Women must feel that the systems are open, available, and accessible. Neither of the networks can adequately respond to the needs of women who are the victims of abuse. Elder abuse workers in APS are not trained in domestic violence and domestic violence workers are not trained in the issues of aging. An integrated program is needed in order to expand the options available to women and close the gaps created in the system. Additionally, public health programs need to educate women to broaden their own perspective of options. The expansion of services must incorporate the strengths of both systems. The use of shelters may be expanded as a place of respite from caregiver stress as well as a place where an older victim can be guaranteed safety from acts of domestic violence. Recommendations for shelters specifically created for older women are imperative.

Workers must be trained to understand the complications of domestic violence which include issues of safety, protection, and assessment of risk. APS workers must be trained to understand the mental health complications of domestic violence and issues of safety and protection, and DV workers need to understand the specific needs of older women, including concerns about mental and physical health, specific responses to loss, and requirements for peer support. Particular needs for policies and programs created without the collaboration of representatives from APS, DV, and those who have participated as clients within the systems should take precedence in planning for expansion of services. Reporting should become centralized with assistance given to those workers who are reluctant to report due to concerns regarding confidentiality with their clients.

Further research needs to be completed and should include women from ethnic minorities. The research must also be geared to include the perceptions of women who have been abused so that they are understood. Services can then be tailored to meet their needs and perhaps help them to heal as well as resolve the problem of abuse.

\section{References}

Beaulaurier, R., Seff, L., Newman, F., \& Dunlop, B. (2007). External barriers to help seeking for older women who experience intimate partner violence. Journal of Family Violence, 22(8), 747-755.

Brandl, B. (2005). Mandatory reporting of elder abuse: Implications for domestic violence advocates. Retrieved from http://www.ncall.us/docs/Mandatory_ Reporting_EA.pdf

Brandl, B., \& Cook-Daniels, L. (2002). Domestic abuse in later life. Washington, DC: National Resource Center on Domestic Violence.

Coyne, A. C., Reichman, W. F., \& Berbig, L. J. (1993). The relationship between dementia and elder abuse. American Journal of Psychiatry, 150, 643-663. 
Grossman, S. F., \& Lundy, M. (2003). Use of domestic violence services across race and ethnicity by women 55 and older: The Illinois experience. Violence Against Women, 9(12), 1442-1452.

Hightower, J. (2002). Violence and abuse in the lives of older women: Is it elder abuse or violence against women? [Background paper]. INSTRAW electronic discussion forum: Gender aspects of violence and abuse of older persons. Retrieved from http://www.un-instraw.org/ageing/discussion_forum.html

Illinois Department on Aging. (2009). What is elder abuse? Retrieved February 5, 2009, from http://www.cbrx.il.gov/aging/labuselegal/abuse_what-is.htm

Kilbane, T. (2007, September). Bridges multiple systems' response to abuse report against older women. Paper presented at the NASW 2007 Bi-Annual Statewide Conference.

Klein, A., Tobin, T., Salomon, A., \& DuBois, J. (2007). A statewide profile of abuse of women and the criminal justice response [Unpublished report to the U.S. Department of Justice]. Sudbury, MA: Advocates for Human Behavior.

Lundy, M., \& Grossman, S. F. (2004) Elder abuse: Spouse/intimate partner abuse and family violence among elders. Journal of Elder Abuse and Neglect, 16(1), 85-102.

Moon, A., \& Benton, D. (2000). Tolerance of elder abuse and attitudes toward thirdparty intervention among African American, Korean American and White elderly. Journal of Multicultural Social Work, 8(3/4), 283-303.

National Center on Elder Abuse. (2006). Abuse of adults aged 60+ 2004 survey of adult protective services [Fact sheet]. Retrieved February 5, 2009, from http://www. ncea.aoa.gov/NCEAroot/Main_Site/pdf/2-14-06\%2060FACT\%20SHEET.pdf

Nerenberg, L. (2002). The national policy summit issue briefs. Journal of Elder Abuse and Neglect, 14(4), 71-104.

Otto, J. M., \& Quinn, K. (2007). Barriers to and promising practices for collaboration between adult protective services and domestic violence programs [A report for the National Center on Elder Abuse]. Retrieved February 2, 2009, from http:// www.ncea.aoa.gov/NCEAroot/Main_Site/pdf/BarrierstoPromisingPractices.pdf

Paranjape, A., Tucker, A., McKenzie-Mach, L., Thompson, N., \& Kaslow, N. (2007). Family violence and associated help-seeking behavior among older African American women. Patient Education and Counseling, 68, 167-172.
Paveza, G. J., Cohen, D., \& Eisdorfer, C. (1992). Severe family violence and Alzheimer's disease: Prevalence and risk factors. Gerontologist, 32(4), 493-497.

Pillemer, K., \& Finkelhor, D. (1989). Causes of elder abuse: Caregiver stress versus problem relatives. American Journal of Orthopsychiatry, 59(2), 179-187.

Rennison, C. M., \& Rand, M. (2003). Non-lethal intimate partner violence against women: A comparison of three age cohorts. Violence Against Women, 9(12), 1417-1428.

Vinton, L. (1991). Factors associated with refusing services among maltreated elderly. Journal of Elder Abuse and Neglect, 3(2), 89-102.

Wisconsin Coalition Against Domestic Violence. (2006). Primary prevention and social change. Education Journal, 26(3). Retrieved from http://www.wcadv.org

Wolf, R. (1998). Support groups for older victims of domestic violence: Sponsors and programs. Washington, DC: National Center on Elder Abuse.

Wood, E. (2006). The availability and utility of interdisciplinary data on elder abuse: A white paper for the National Center on Elder Abuse. Retrieved February 5, 2009, from http://www.ncea.aoa.gov/NCEAroot/Main_Site/pdf/publication/ WhitePaper060404.pdf

Zarit, S., \& Toseland, R. (1989). Current and future direction in family caregiving research. The Gerontologist, 29, 481-483.

Teresa Kilbane, $\mathrm{PhD}$, is associate professor, and Marcia Spira, $\mathrm{PhD}$, is associate professor, Loyola University Chicago. Correspondence regarding this article can be sent to the second author at mspira@luc.edu or Loyola University Chicago, 111 E. Pearson, IL 60611

Manuscript received: February 9, 2009

Revised: July 1, 2009

Accepted: July 2, 2009

\section{Online Learning: \\ Affordable, Accessible, Convenient}

CE4Alliance is an online continuing education program designed to help satisfy licensing and certification requirements with automated online exams, online scoring, and certificate printing.

Flexibility and affordability are additional advantages to this program, which provides competent, consistent, and interdisciplinary learning.

\section{Stay up-to-date - Learn from innovators - Earn credits}

\section{Benefits for Professionals and Agencies :}

- Cost-effective training and staff development opportunities.

- Quick, easy, and convenient access to a versatile continuing education format.

- Funders and accreditation services value a commitment to excellence and continuous quality improvement (CQI).

- A more informed and educated workforce.

- Compliments offsite CE seminars and workshops for a fraction of the cost.

- Pre-purchased course coupons can be distributed to staff. Specific courses can be selected as mandatory for employees.

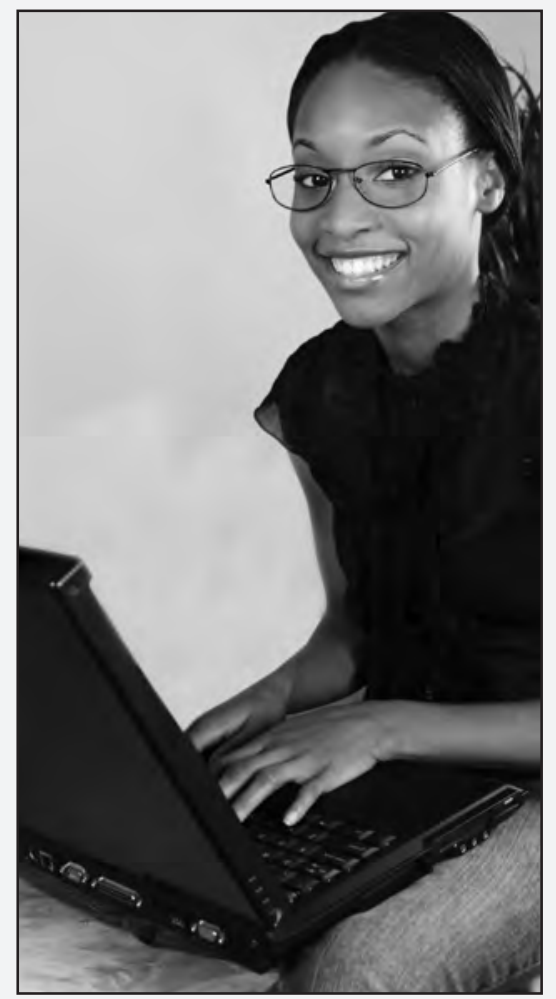

CE4Alliance is provided by Families in Society and its publisher, the Alliance for Children and Families. FamiliesInSociety.org - Alliance1.org 